ance described already in the case of the round-cell sarcoma (Figure 3). Owing to their distention with pus or cheesy products the vertical columns are easily recognized.

Whether the so-called "core" of a boil may not be the necrosed fragment of cutis cut off from its blood supply by the obliteration of one or more of these canals by inflammatory products, I have had no opportunity yet to determine. Whether the situation of vesicles or papules in a cutaneous eruption correspond in any way to the distribution of these canals is also a subject for future inquiry.

In a case of melanotic sarcoma of the skin of the back, situated just beneath the corium, a number of sections were made to observe the progress of the disease downwards through the skin. Although the canals were numerous, the disease had hardly reached a sufficient depth to determine to what extent its further progress might have been modified by these structures. In those directly beneath the tumor a small, round-cell infiltration was observed in one or two instances. The more malignant form of cancer of the skin, of which cancer of the lip is the type, might be found to traverse these canals. In the lip and penis, however, the canals would not be found. When occurring on other parts of the skin, on the back of the hand, as it occasionally does, it might be studied to advantage.

In drawings of vertical sections of the skin irregularities of contour are sometimes to be seen at the line of junction of the adipose layer with the cutis vera, or irregularities in the arrangement of the fibres of the cutis, indicating that the section has been made near a canal. I have been unable, however, to find any description of these fat canals in modern text-books or recent periodical literature.

The drawings were made by Dr. H. P. Quincy from sections prepared by him. The experiments were performed in Professor Bowditch's laboratory.

\title{
A CASE OF HYDROPHOBIA.
}

BY SANDFORD HANSCOM, M. D., EAST GOMERVILLE.

ON the morning of the 20th of November a good-natured pet spaniel, which had never been known to snap at any one, suddenly and without any provocation sprang at his mistress. His master whipped him, and he was left in the cellar of the house until the time for his dinner. While eating it in the company of a pet cat, as he had been accustomed to, without ever having molested her, he suddenly seized the cat and threw her across the room. The owner reached out his hand to catch the dog, when the latter caught him tightly by the wrist and inflicted a deep wound, biting him three times; the skin became lacerated while making an effort to shake him off. It was supposed at 
the time that the dog was irritable from the whipping which he had received in the morning, and as he expected another, for snapping at the cat, defended himself by biting. Half an hour after, the patient applied to me for treatment, and believing it to be too late for excision or cauterization to be effective, and as there was no history of hydrophobia, I dressed the wound with a solution of carbolic acid. It healed readily, and the patient attended to his business as usual in four or five days. Soon after the infliction of the bite the dog disappeared and he did not return for thirty-six hours; nothing could be ascertained of his whereabouts or of his behavior during that time. When he returned he was very much exhausted, and had the appearance of having been severely beaten. From what I can learn of those who saw him he gradually grew weaker, apparently losing the use of his legs, especially the hind ones, which he would drag after him. He died quietly, with his head in the lap of his mistress, without having had a convulsion, excessive flow of saliva, or tremors. On the 13th day of January (fifty-four days after the injury), the patient began to have shooting pains in the fore-arm, but not especially localized. They did not radiate from the cicatrix, and there was no change in the appearance of the latter. On the following day the pain had increased so much that he required one sixth of a grain of morphia to relieve him; it was given subcutaneously, and was repeated the next morning. After that there was very little pain in the arm, and no appreciable change in the pulse or temperature. He was despondent, and stated on the morning of the 15th that "he felt sick and used up all over ;" he was obliged to go to bed in the afternoon, and then for the first time began to have some difficulty in swallowing. This symptom was not manifested by an attempt to drink water, but during an effort to swallow some herb tea that he was accustomed to take when ill, and which he believed would relieve his bad feelings. There was no trismus; he was quiet and inclined to doze. At five P. M. Dr. H. H. A. Beach saw the patient with me, and agreed that the history of the case in connection with the symptoms then existing indicated the probable development of hydrophobia, and an unfavorable prognosis was given to the patient's brother, who promised not to communicate it to the patient or his friends until the disease should be fully declared. His pulse at that time was 102, and the temperature in the axilla $102^{\circ} \mathrm{F}$, face flushed, tongue coated. The cicatrix presented no unusual appearance, nor was it tender. $A$ dark room was agreeable to him, but on raising the curtains the light did not disturb him in the least. $\mathrm{He}$ was perfectly rational and had some thirst, but no sore throat. He made an attempt to swallow a teaspoonful of milk, but was obliged to give it up from the moment that the fluid touched his lips. Immediately after this attempt unmistakable spasmodic contraction of muscles between the chin and sternum was observed. Mentally the patient 
was perfectly clear and not disturbed by the unsuccessful attempt at swallowing fluids, but said he would try it again when he should be more thirsty. This symptom, excepting when he swallowed teaspoonful doses of medicine, continued until his death. He was obliged to relieve his thirst by sucking ice and snow through a napkin. The air from a fan or from adjusting the bed-clothing caused a shudder. Occasional sighing was noticed after the second day; it grew deeper and more frequent until the end. When disturbed from any cause his respiration was of a spasmodic character, so much so at times as to interfere with his speech.

On the following morning (the 16th) his pulse was 96 , and mild delirium first developed; this also continued until his death. He was easily controlled throughout the disease. He became very suspicious of the people about him, believing that they were attempting to make him the victim of practical jokes, then of being poisoned. One hallucination was continuous from the time that the delirium first developed; he thought that some one had thrown a dirty powder on him, and he was continually making efforts to shake it off from himself and his clothing. He was also very cross and dictatorial, but showed no disposition to snap or bite.

Between four and five P. M. on the 18th he began to have spasmodic contraction of the muscles of the chest, larynx, and throat; some of them lasted nearly a minute, and prevented him from taking an inspiration. He also had a profuse discharge of saliva sufficient to wet his clothing through from his chin down to his hips. The spasmodic contractions concerned in respiration exhausted him rapidly, and he died quietly at 8.15 , while sitting up in a chair. This position became necessary from the fact that he could not lie on his side, and if on his back the saliva accumulated so rapidly that it obstructed his respiration. For the last twenty minutes before his death there was no spasm. He lived five days after the first general symptom. At no time was he disturbed by the sound of ringing bells or running water. Morphia in one-fourth-grain doses, and chloral and bromide of potassium in fifteen-grain doses of each at the same time were given as needed. Anæsthetics were not required. At the solicitation of his friends he was allowed to take a pill, the prescription for which was said to be one hundred years old and to have cost originally five hundred pounds. It had the reputation of curing and preventing many cases of the disease. No change in his symptoms could be attributed to its action, nor could its composition be ascertained. It was given as a placebo, on the chances that a hysterical element existed in this case; that whatever offered encouragement to the patient without the possibility of injury in his hopeless condition was justifiable, but so far as the evidence furnished by one case is of value its inefficacy was demonstrated. The permis- 
sion of the friends for an autopsy could not be obtained. The particular symptoms of the disease which were not observed in the dog when seen might have existed during the thirty-six hours that he was absent. ${ }^{1}$

The proximity of the wound to the ulnar nerve and its character (punctured and lacerated) suggested the consideration of tetanus as an explanation of the symptoms; the latter seemed to be fairly excluded, however, on the ground that delirium was continuous from the third day of the attack, and that at no time did trismus or any other form of tonic spasm exist; the profuse discharge of saliva was also corroborative of this view. The unquestionable existence of repeated attacks of laryngeal spasm; the fact that the symptoms developed after a considerable interval had elapsed from the date of the injury; that for three hours previous to his death, and after he became wholly unconscious, marked spasms of the chest and throat occurred at intervals of from three to five minutes; that death occurred as a result and within five days following the development of symptoms characteristic of the disease, reasonably offsets a theory that the hydrophobic symptoms were simulated by a hysterical man.2

$1 \mathrm{Mr}$. Youatt's description has been the one most uniformly accepted and quoted. He says: "The disease manifests itself under two forms : the furious form, characterized by augmented activity of the sensorial and locomotive systems, a disposition to bite, and a continual peculiar bark. The animal becomes altered in habits and disposition, has an inclination to lick or carry inedible substances, is restless, and snaps in the air, but is still obedient and attached. Soon there are loss of appetite and the presence of thirst, the mouth and tongue swollen; the eyes red, dull, and half-closed; the skin of the forehead wrinkled; the coat rough and staring; the gait unsteady and staggering; there is a periodic disposition to bite; the animal in approaching is often quiet and friendly, and then snaps; latterly, there is paralysis of the extremities; the breathing and deglutition become affected by spasms ; the external surface irritable, and the sensorial functions increased in activity and perverted; convulsions may occur. These symptoms are paroxysmal, they remit and intermit, and are often excited by sight, hearing, and touch.

"The sullen form is characterized by shyness and depression, in which there is no disposition to bite and no fear of fluids. The dog appears to be unusually quiet, is melancholy and has depression of spirits; although he has no fear of water he does not drink; he makes no attempt to bite, and seems haggard and suspicious, avoiding society and refusing food. The breathing is labored, and the bark is harsh, rough, and altered in tone; the mouth is open from the dropping of the jaw; the tongue protrudes, and the saliva is constantly flowing. The breathing soon becomes more difficult and laborious; there are tremors, and vomiting, and convulsions." - (Holmes's Surgery, vol. i., page 685.)

2 "As regards the diagnosis, there is no particular symptom which can be relied upon as forming a distinguishing mark of this disease ; the symptoms must be taken collectively, and then there is no disease simulating it ; thus the peculiar combination of disturbance of the muscles of the pharynx and larynx, the psychical hyperasthesia and fear, the altered voice, the difficult breathing and swallowing, the perverted appetite, the hallucination, and the easily excited rage are for the most part the diagnostic signs. The dread of water, the almost characteristic symptom in man, is not always present, as may be proved in recorded cases. On the other hand, this symptom may be met with in other diseases; thus in hysteria we may bave what is called hysterical hydrophobia, where the sight of water induces a paroxysm of hysteria, but this only lasts a short time." - (Holmes's Surgery, vol. i., page 691.) 